\title{
Study on $R-\mu-T$ Models in Predicting the Displacement Demand of a Hybrid Structure
}

\author{
Ying Zhou ${ }^{1}$ Xilin $\mathrm{Lu}^{*^{2}}$ and Zhihua Huang ${ }^{3}$ \\ ${ }^{1}$ Associate Professor, State Key Laboratory of Disaster Reduction in Civil Engineering, Tongji University, China \\ ${ }^{2}$ Professor, State Key Laboratory of Disaster Reduction in Civil Engineering, Tongji University, China \\ ${ }^{3}$ Doctoral Student, College of Civil Engineering, Tongji University, China
}

\begin{abstract}
The relationship of the strength reduction factor $R$, the displacement ductility $\mu$, and the structural period $T$ is of significance in predicting the structural demand by the method of inelastic response spectrum analysis (RSA). So far eight $R-\mu-T$ models have been proposed by researchers worldwide; however, no comparisons among them have been performed for the improvement of future models. This paper compared eight $R-\mu-T$ models from three aspects: parameters to build the models, model results under constant ductility, and response predictions for a high-rise hybrid structure with reinforced concrete core walls at the center and steel frame at the periphery. From these comparisons, it is concluded that the difference between the displacements obtained by the inelastic RSA of eight models and the elasto-plastic time history analysis is within $30 \%$. Thus, inelastic RSA can work as an effective method in predicting the displacement demand of structures. The influence of the hysteretic model on the $R-\mu-T$ relationship is not obvious, but the site characteristics do have an effect on the results of various $R-\mu-T$ models with a maximum difference of $25 \%$. Because no unanimous agreement has been reached regarding the effect of the damping, further research on the damping of the single-degree-of-freedom system to build the model is needed.
\end{abstract}

Keywords: displacement demand; inelastic response spectrum analysis; $R-\mu-T$ model; high-rise hybrid structure; site characteristics

\section{Introduction}

Displacement-based seismic design (DBSD) is a subset of the performance-based seismic design (PBSD) of structures (Ghobarah, 2001). Its design process starts from structure to members to fulfill the desired performance objectives. First, according to the desired performance objectives, the structural global displacement demand is determined. Then the displacement demand of the structure is transferred to the deformation demand of the structural members. Based on the relationship of section deformation and curvature, member design is carried out. It can be seen that how to determine the structural displacement demand simply and reasonably is the first key step in the DBSD process.

Response spectrum analysis (RSA) is a simplified method to estimate the structural response under specific earthquake levels. The elastic response spectrum is created to predict the maximum seismic responses of a single-degree-of-freedom (SDOF) system with various periods. For a multi-degree-of-freedom (MDOF)

*Contact Author: Xilin Lu, Professor, State Key Laboratory of Disaster Reduction in Civil Engineering, Tongji University, 1239 Siping Road, Shanghai 200092, China

Tel: +86-21-65983430 Fax: +86-21-65982668

E-mail: 1xlst@tongji.edu.cn

(Received April 11, 2011 ; accepted January 12, 2012) system, the seismic response can be calculated by the mode-superposition response spectrum method. The method is that, due to the orthogonality of vibration modes, the MDOF system is decoupled into multiple individual SDOF systems. Then the responses of these SDOF systems are calculated by the elastic RSA. The SDOF responses are combined through the principle of square root of the sum of squares (SRSS) to obtain the response of the MDOF system. With the development of the seismic concept from elastic to inelastic, however, researchers have begun studies on the inelastic response spectrum analysis.

The essence of inelastic RSA is to introduce parameters to consider the structural elasto-plastic development on the basis of elastic RSA. Its usual practice is as follows.

(1) According to the model pushover analysis (MPA), instead of the orthogonality of vibration modes, the MDOF system is decoupled into multiple individual SDOF systems. The yield strengths and yield displacements under individual vibration modes are then calculated.

(2) The ratios of the maximum elastic force to the yield strength, which is defined as strength reduction factor $R$, are obtained for individual vibration modes.

(3) If $R$ of a vibration mode is less than 1, that is to say, the model is still in the elastic range and elastic RSA can be applied to analyze the structural response. If $R$ of a vibration mode is larger than 1 , then the model has 
entered the elasto-plastic stage. The structural response will be obtained by the elastic response multiplied by a ductility coefficient $\mu$. $\mu$ is defined as the ratio of the maximum displacement to the yield displacement and it can be calculated from the relationship among the strength reduction factors $R$, ductility coefficient $\mu$, and structural period $T(R-\mu-T$ model $)$.

(4) The SDOF responses are combined through the SRSS principle to obtain the inelastic response of the MDOF system.

From the process above, it can be seen that the application of MPA and $R-\mu-T$ model are two significant steps that will affect the results of inelastic RSA.

In the 1990s, the seismic demands were computed by pushover analysis (POA) of the structure subjected to monotonically increasing lateral forces with an invariant height-wise distribution until a predetermined target displacement was reached. Both the force distribution and target displacement are based on the assumption that the response is controlled by the fundamental mode and that the mode shape remains unchanged after the structure yields. Obviously, after the structure yields, both assumptions are approximate. A modal pushover analysis (MPA) procedure was proposed by Chopra and Goel (2002). In MPA, the seismic demand due to individual terms in the modal expansion of the effective earthquake forces is determined by a pushover analysis using the inertia force distribution for each mode.

On the other hand, the elastic RSA is influenced by the structural period, ground motion characteristics, and site soil type, while the inelastic RSA is also affected by the yield strength and yield displacement of the structure. Thus, ductility coefficient $\mu$ was introduced in the inelastic RSA and various $R-\mu-T$ models were proposed with the considerations of different ground motion records, hysteretic models, and damping ratios (Newmark and Hall, 1973; Nassar and Krawinkler, 1991; Miranda, 1993; Fajfar and Vidic, 1994; Borzi and Elnashai, 2000; Zhuo and Fan, 2001; Lu and Zhou, 2004; Zhai and Xie, 2006). Until now, no comparison has been studied to analyze the results of these $R-\mu-T$ models.

The intent of this paper is to compare the effecting parameters and analytical results of existing $R-\mu-T$ models from three aspects. First, the eight $R-\mu-T$ models listed above are compared regarding their parameters to build the models, including the number of ground motions, parameters of SDOF systems, and the site soil considerations. Then, they are analyzed under two constant ductility cases. The applications of eight models on a highrise building, which has central reinforced concrete (RC) core walls and a peripheral steel frame structural form, are also performed to quantify the difference in the structural responses.

\section{Method of Modal Pushover Analysis \\ 2.1 MPA process}

The MPA method was put forward by Chopra and
Geol (2002). Its basic process is: a nonlinear MDOF structural system is equalized to multiple SDOF systems; POA is performed under individual modes to obtain the POA curves of the base shear and roof displacement; and as suggested by FEMA 273 (1997), POA curves are simplified into bilinear curves to determine the yield base shear force $V_{b y}$ and yield roof displacement $u_{r y}$ (Fig.1.). The equations and figures of the MPA are listed below for analysis later. Chopra and Geol's paper should be referred to concerning the detailed theoretical background of the method.

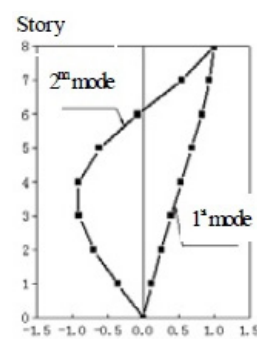

(a)

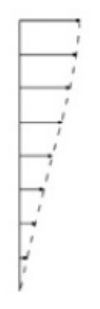

(b)

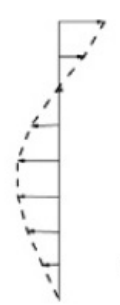

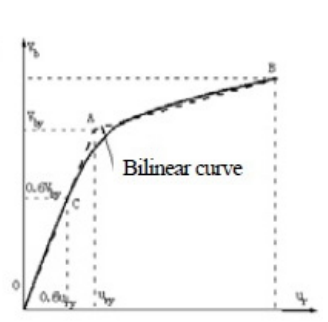

(c)
Fig.1. Procedure of Modal Pushover Analysis: (a) Elastic Mode; (b) Lateral Force or Displacement Distribution; and (c) Simplified Bilinear Curve

\subsection{Equivalent SDOF systems}

The first step of the MPA method is to equalize a nonlinear MDOF structural system to multiple SDOF systems. Every equivalent SDOF system corresponds to one vibration mode. According to the dynamics of structures, there is:

$m \ddot{u}+c \dot{u}+f_{s}=-m l \ddot{u}_{g}(t)$

where $u$ is the vector of $\mathrm{N}$ lateral floor displacements relative to the ground, $m$ and $c$ are the mass and damping matrices of the systems, $f_{s}$ is the lateral floor force and $f_{s}=f_{s}(u), \ddot{u}_{g}(t)$ is the time history of ground acceleration, and each element of the influence vector $l$ is equal to unity.

$$
u(t)=\sum_{1}^{n} q_{n}(t) \varphi_{n}
$$

Substituting Equation (2) into Equation (1) and left multiplying $\varphi^{T}$, when $D_{n}=q_{n} / \Gamma_{n}$, gives,

$$
\ddot{D}_{n}+2 \xi_{n} \omega_{n} \dot{D}_{n}+F_{s n} / L_{n}=-\ddot{i}_{g}(t)
$$

where $F_{s n}=\varphi_{n}^{T} f_{s}$ and $\Gamma_{n}$ is the mode participation factor. There is,

$$
\Gamma_{n}=L_{n} / M_{n}, \quad L_{n}=\varphi_{n}^{T} m l, \quad M_{n}=\varphi_{n}^{T} m \varphi_{n}
$$

It can be seen that the one premise for MPA is that the orthogonality of vibration modes still stands even if the structure yields. Thus, Equation (3) is decoupled and the problem is substantially simplified. By now, the $\mathrm{N}$ equivalent SDOF systems are built.

\subsection{Yield force and yield displacement}

After performing pushover analysis under individual modes, another key problem for MPA is how to transfer 
the relationship of base shear and roof displacement $\left(V_{b n}-u_{r n}\right)$ to the relationship of yield force and yield displacement $\left(F_{s n} / L_{n}-D_{n y}\right)$. Since the floor lateral force is proportional to the product of the vibration amplitude and story mass, the $i^{\text {th }}$ floor lateral force can be expressed as Equation (5).

$$
f_{s i}=\frac{m_{i} \varphi_{i}}{\sum m_{i} \varphi_{i}} V_{b n}
$$

Thus,

$$
F_{s n}=\varphi_{n}^{T} f_{s}=\frac{V_{b n}}{\Gamma_{n}}
$$

The yield force and yield displacement can be expressed as Equation (7) and (8), respectively.

$$
\begin{aligned}
& F_{s n} / L_{n}=\frac{V_{b n}}{\Gamma_{n} L_{n}} \\
& D_{n y}=\frac{u_{r y y}}{\Gamma_{n} \varphi_{m}}
\end{aligned}
$$

where $\varphi_{r n}$ is the roof vibration amplitude.

Considering the following equation,

$$
F_{s n y} / L_{n}=\omega^{2} D_{n y}
$$

The periods of the equivalent SDOF systems are,

$$
T_{n}=2 \pi \sqrt{L_{n} D_{n y} / F_{s n y}}
$$

It should be noted that there would be quite a difference between the periods of the equivalent SDOF systems and the periods calculated from the structural elastic stiffness. In the Chinese code, the elastic stiffness of structures is applied to obtain the structural periods. However, RC members usually work with invisible cracks and serve in the elasto-plastic stage. The real stiffness of the structure is obviously overestimated by applying the elastic stiffness, which leads to a shorter period and conservative displacement. Application of the periods of equivalent SDOF systems in the MPA method, synthesizes to some extent, the effect of stiffness.

\section{Inelastic Response Spectrum}

The inelastic SDOF response relates to the yield strength. Normalized parameters are usually employed to describe the structural yield strength to make the result more general. For example, various parameters were proposed on the basis of ground motions. The usual one is to normalize the yield strength corresponding to the elastic acceleration. That is,

$$
\xi_{y}=\frac{F_{y}}{m \cdot S_{a}}=\frac{F_{y}}{F_{e}}=\frac{1}{R}
$$

where $R$ is the strength reduction factor, $\xi_{y}$ is the yield strength factor, and $F_{y}$ is the yield strength.

Miranda (1993) further normalized the yield strength to the peak ground acceleration (PGA) to obtain the yield degree factor $\eta$.

$$
\eta=\frac{F_{y}}{m \cdot P G A}
$$

From Equation (12) and (13), there is,

$$
R=\frac{S_{a}}{P G A} \cdot \frac{m \cdot P G A}{F_{y}}=\frac{\beta}{\eta}
$$

where $\beta$ is the dynamic amplification factor.

Since we define the structural ductility factor as the ratio of the maximum displacement to the yield displacement, that is,

$$
\mu=\left|u_{\max }\right| / u_{y}
$$

Substituting Equation (13) into Equation (14), gives,

$$
\ddot{\chi}+\frac{4 \pi}{T} \xi \dot{\chi}+\frac{4 \pi^{2}}{T^{2}} q(\chi)=-\frac{4 \pi^{2}}{T^{2}} \cdot \frac{R}{\beta} \tau(t)
$$

Equation (15) reflects the relationship among the strength reduction factor $R$, ductility factor $\mu$ and structural period $T$. If $R$ is held as a constant, the displacement ductility $\mu$ under different periods $T$ can be obtained to form constant- $R$ demand spectrum. Meantime, holding $\mu$ as a constant, the strength reduction factor $R$ under different periods $T$ can be obtained to form constant $\mu$ demand spectrum.

\section{4. $R-\boldsymbol{\mu}-\boldsymbol{T}$ Model}

\subsection{Model parameters}

By now, different $R-\mu-T$ models have been proposed by researchers (Newmark and Hall, 1973; Nassar and Krawinkler, 1991; Miranda, 1993; Fajfar and Vidic, 1994; Borzi and Elnashai, 2000; Zhuo and Fan, 2001; Lu and Zhou, 2004; Zhai and Xie, 2006). Table 1. lists the eight models in the order of time. From Table 1., it can be seen that:

(1) Ground motions. Only three pulse excitations are considered to build the Newmark-Hall model, while tens of ground motions are used in the other seven models.

(2) Parameters of SDOF systems. Bilinear hysteretic models are applied in SDOF systems to obtain seven $R-\mu-T$ model parameters, while the bilinear and trilinear relationship is employed for the Borzi-Elnashai model. Also, the stiffness degradation is considered in the Nassar-Krawinkler model, Fajfar-Vidic model, Zhuo-Fan model and Lu-Zhou model. The influence of the hysteretic model on the $R-\mu-T$ relationship is not obvious. Miranda's study found that for the SDOF ductility system the effect of the hysteretic model, post-yield stiffness, strength degradation, and stiffness degeneration can be neglected. The same results were obtained from the earthquake energy analysis by Sucuoglu et al. (1994). They concluded 
Table 1. Comparison of $R-\mu-T$ Models

\begin{tabular}{lccccccc}
\hline \multicolumn{1}{c}{ Model } & Year & $\begin{array}{c}\text { The number of } \\
\text { ground motions } \\
\text { (pulse excitation) }\end{array}$ & $\alpha(\%)$ & $\begin{array}{c}\text { Hysteretic } \\
\text { model }\end{array}$ & $\begin{array}{c}\text { Stiffness } \\
\text { degradation }\end{array}$ & $\beta(\%)$ & $\mu$ \\
\hline Newmark-Hall & 1973 & $(3)$ & 0 & Bilinear & - & $\leq 20$ & $\leq 10$ \\
Nassar-Krawinker & 1991 & 15 & $0,2,10$ & Bilinear & SD & 5 & $\leq 8$ \\
Miranda & 1993 & 124 & 3 & Bilinear & - & 5 & $\leq 6$ \\
Fajfar-Vidic & 1994 & 40 & 10 & Bilinear & SD & 5 & $\leq 10$ \\
Borzi-Elnashai & 2000 & 364 & $0,10,-20,-30$ & Trilinear & - & 5 & $\leq 6$ \\
Zhuo-Fan & 2001 & 327 & 0 & Bilinear & SD & 5 & $\leq 8$ \\
Lu-Zhou & 2004 & 641 & 2 & Bilinear & SD & 5 & - \\
Zhai-Xie & 2006 & 823 & $0,5,10$ & Bilinear & - & $2,5,10$ & $\leq 6$ \\
\hline
\end{tabular}

where $\alpha=$ post-yield stiffness ratio; $\beta=$ damping ratio; $\mathrm{SD}=$ stiffness degradation; $\mathrm{SC}=$ soil condition

that displacement ductility and damping ratio are two key factors to affect the strength reduction factor $R$. However, no unanimous conclusions are reached on the effect of the damping (damping model and damping ratio) on the $R-\mu-T$ relationship. Most models simply take $5 \%$ as the damping ratio into consideration.

(3) Soil condition. The soil condition is included in four $R-\mu-T$ models, including the Miranda model, Zhuo-Fan model, Lu-Zhou model, and Zhai-Xie model. The influence of the seismic intensity, epicenter distance, and site characteristics on the $R-\mu-T$ model is not consistent. It is agreed that the effect of seismic

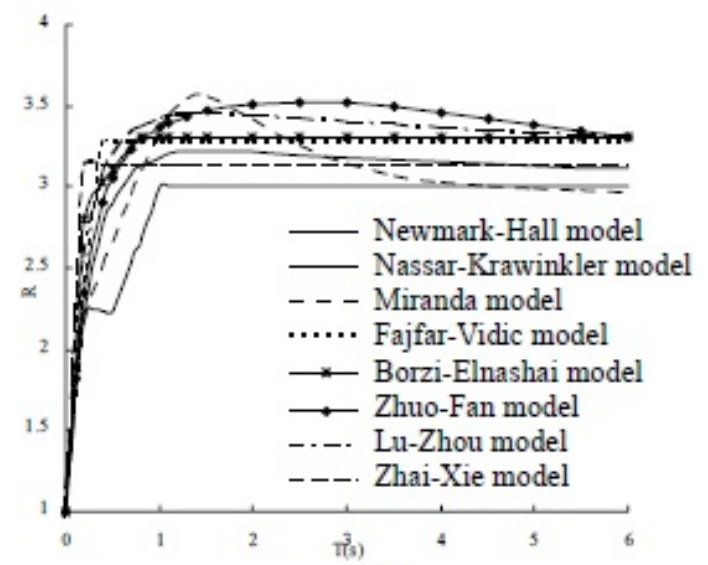

(a)

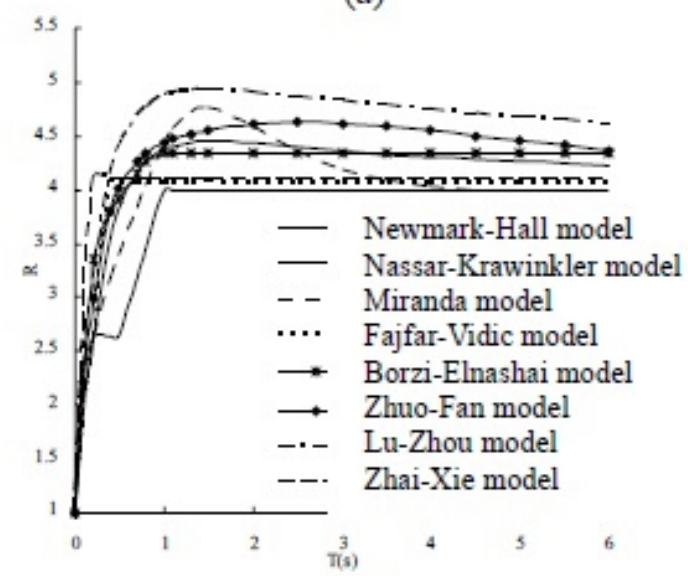

(b)

Fig.2. Comparison of Eight $R-\mu-T$ Models Under Constant Displacement Ductility: (a) $\mu=3$; and (b) $\mu=4$ intensity and epicenter distance can be neglected; however, that of site characteristics is not unified. Some researchers (Borzi and Elnashai, 2000) thought that site characteristics do have an apparent effect on both elastic and inelastic response spectrum, but do not affect their ratio $R$. Some (Miranda, 1993; Zhuo and Fan, 2001; $\mathrm{Lu}$ and Zhou, 2004; Zhai and Xie, 2006) agreed that site characteristics have a deep influence on the $R-\mu-$ $T$ model. Especially for soft soil, the value of $R$ would become small for a short period.

\subsection{Model results under constant ductility}

Taking the soil condition of bed rock as an example, the comparison of those models with a displacement ductility of $\mu=3$ and $\mu=3$ is shown in Fig.2.

It can be found that at the periods of $0-0.12 \mathrm{~s}$, the models agree well with each other. From $0.12 \mathrm{~s}$ to $1 \mathrm{~s}$, the models show an abrupt difference. The NewmarkHall model gives the smallest result while the Lu-Zhou model predicts the largest, the difference of which is $25-40 \%$. At the stage of 1-6s, the Newmark-Hall model is still small. The Lu-Zhou model and Zhuo-Fan model are quite large, with a difference of $15-20 \%$. Therefore, the Newmark-Hall model is conservative at the medium and long period. Another phenomenon should be noted that although the soil conditions are considered in the four models given above, the Zhai-Xie model always provides a more conservative result than the other three models at the long period. The reason lies in the difference in the basic expression of the models. (Miranda, 1993; Zhuo and Fan, 2001; Lu and Zhou, 2004; Zhai and Xie, 2006).

\section{Displacement Demand of a High-Rise Hybrid Structure}

In recent years, hybrid structural systems, with RC core walls in the center and steel frames at the periphery, are popular in China for 30 to 60 story buildings. The system has an advantage through its good combination of steel and concrete in the plan layout. Here a hybrid structure is introduced as an example to estimate the displacement demand by the Lu-Zhou model and compare the difference with various $R-\mu-T$ models.

\subsection{Hybrid structural system}

The structure has fifteen stories with a story height of $4 \mathrm{~m}$ and its typical plan layout is shown in Fig. 3 . The concrete grade is $\mathrm{C} 40$ with a design compressive 
strength of 19.1 MPa. The material of longitudinal and transverse reinforcement are Grade II and Grade I with a nominal yield stress of $310 \mathrm{MPa}$ and $210 \mathrm{MPa}$, respectively. For the steel frame, the beams and columns are made of Q345 with specified yield strength 345 $\mathrm{MPa}$. According to the Load code for the design of building structures (GB 50009-2001) (2001), the dead load for the story floor and roof floor are respectively set as $6.0 \mathrm{kN} / \mathrm{m}^{2}$ and $7.0 \mathrm{kN} / \mathrm{m}^{2}$, while the live load for those are $2.5 \mathrm{kN} / \mathrm{m}^{2}$ and $2.0 \mathrm{kN} / \mathrm{m}^{2}$. The structural member sections are tabulated in Table 2 .

Table 2. Structural Member Sections of Hybrid Structures (units: mm)

\begin{tabular}{|c|c|c|}
\hline Structural members & Section & Section size \\
\hline \multicolumn{3}{|l|}{ Steel column $(\mathrm{b} \times \mathrm{h} \times \mathrm{t})$} \\
\hline & & $400 \times 400 \times 16$ \\
\hline \multicolumn{3}{|l|}{ Steel beam $(b \times h \times t 1 \times t 2)$} \\
\hline & L-A & $400 \times 250 \times 10 \times 16$ \\
\hline q & L-B & $350 \times 230 \times 10 \times 14$ \\
\hline I & $\mathrm{L}-\mathrm{C}$ & $350 \times 200 \times 10 \times 12$ \\
\hline \multirow{4}{*}{ Shear wall (b) } & WY 1 & 200 \\
\hline & $\begin{array}{l}W X-1 \\
W Y-1\end{array}$ & 200 \\
\hline & WY-1 & 220 (Floor 1 3) \\
\hline & WY-2 & 200 (Floor 4 15) \\
\hline \multirow{5}{*}{$\begin{array}{l}\mathrm{RC} \text { connecting beam } \\
\mathrm{B}(=\text { width of the wall }) \times \mathrm{h}\end{array}$} & & \\
\hline & LL-1 & 400 \\
\hline & LL-2 & 650 \\
\hline & LL-3 & 400 \\
\hline & LL-4 & 650 \\
\hline
\end{tabular}

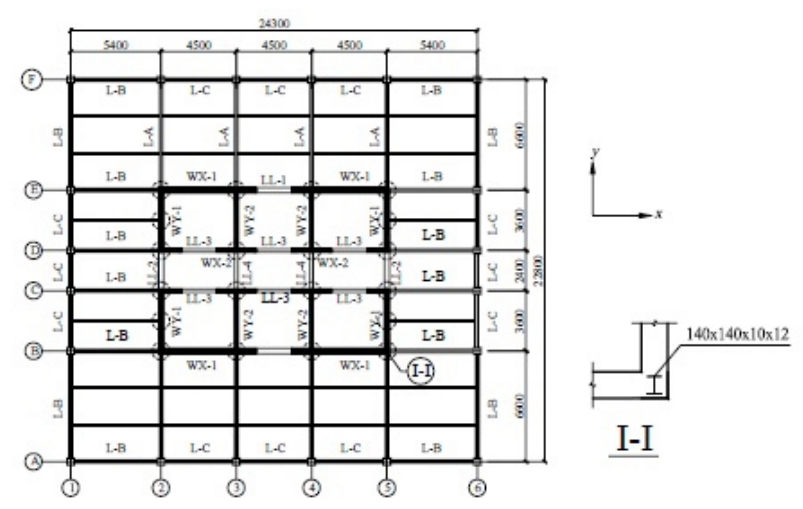

Fig.3. Plan Layout and Section Planes of a Hybrid Structure

\subsection{CANNY model}

In this paper, the structural numerical analysis program CANNY (Li, 2004) is applied. Cases have showed that CANNY is successfully used in the nonlinear analysis of various structural components and systems (Li and Otani, 1993; Li, Kubo and Ventura, 1999).

In the CANNY program, SR4 and CS4 are selected for steel and concrete materials, respectively. The fiber model ( $\mathrm{Li}$ and Kubo, 1998) for the wall element is introduced in the CANNY program. The whole wall with or without attached columns is assumed to maintain its plane section after deformation in the wall plane.
Therefore, the wall contributes stiffness to the vertical displacements at its four corner-nodes, and to the lateral displacements of its base and topsides. At a cross section the lateral translation in the wall plane is assumed to be equal at any point. The wall corner nodes are considered independent of lateral displacement and rotation in the normal direction of the wall-plane. The wall element is idealized by the fiber model that is based on the material characteristics. There are two fiber slices considered at the base and top critical sections, as shown in Fig. 4. Linear distribution of the element flexibility between the two fiber slices is assumed.

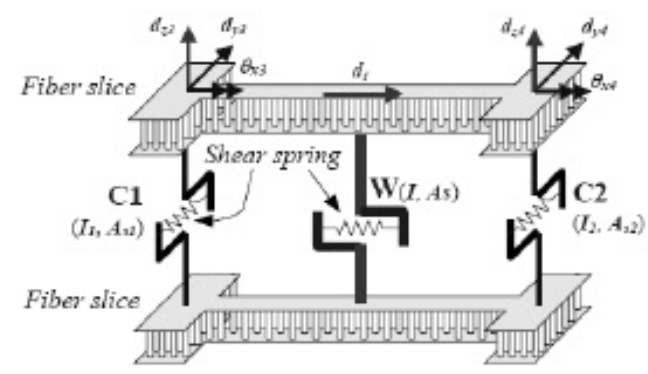

Fig.4. Fiber Model for 3-D Wall Element

The beam element is designed as a uniaxial bending and shear element (2-D element) (Li, 2004). It has stiffness contribution against the flexural and shearing deformation in the element $x-z$ plane, and may have axial stiffness against the deformation in axial tension/compression and in torsion as well. It has no contribution to out-of- $x-z$ plane (free deformation in outof $x-z$ plane). For nonlinear analysis, the beam element is idealized by a one-component model, using the elastoplastic uniaxial spring: two rotational springs at the element-end, and shear and axial springs located in midspan. This results in concentrated nonlinear deformation at the element-end or in the spring.

The column element used in the CANNY program is the 3-D beam model (Li, 2004). It has bi-directional bending and shear and axial deformations (tension/ compression and torsion). The column element can have an arbitrary direction in the space. For nonlinear analysis, the multi-spring model which is known as a simplified discretized-section model is used to idealize the column element. The model combines the effects of a number of uniaxial springs to represent the interactions among multi-directional loads. The model applies individual uniaxial spring based on the force-displacement relation and considers the element nonlinearity at critical sections (lumped nonlinearity model).

The analytical models of hybrid structures are built up as shown in Fig.5. Each model has 576 nodes, 300 column elements, 720 beam elements, and 180 wall elements.

5.3 Decoupling vibration models, yield force and yield displacement

CANNY elastic analysis is performed to obtain the structural dynamic characteristics. The first three natural periods in the $X$ direction are $1.412 \mathrm{~s}, 0.348 \mathrm{~s}$, and $0.149 \mathrm{~s}$, 


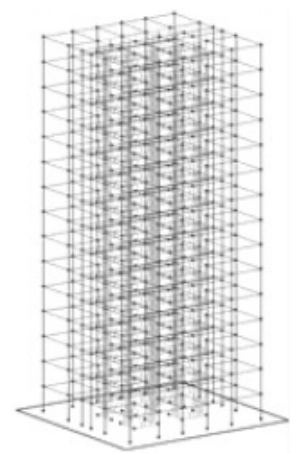

Fig.5. CANNY 3-D Analytical Model

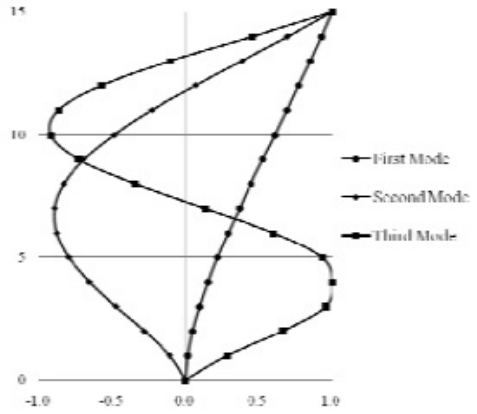

Fig.6. First Three Vibration Mode Shapes in X Direction respectively, and the vibration modes are shown in Fig.6. The structural elastic dynamic parameters are listed in Table 3. The relationship of the base shear and roof displacement of the first three modes in the $X$ direction are shown in Fig.7.

When those curves are simplified as bilinear curves, the yield forces and yield displacements are,

$$
\begin{aligned}
& V_{1 y} / W_{t}=0.102, \quad u_{1 y} / H=0.220 \% \\
& V_{2 y} / W_{t}=0.155, \quad u_{2 y} / H=0.030 \% \\
& V_{3 y} / W_{t}=0.346, \quad u_{3 y} / H=0.022 \%
\end{aligned}
$$

\subsection{Modal periods and elastic base shear of} equivalent SDOF systems

According to the equations in Sections 2.2 and 2.3, the first three mode periods of equivalent SDOF systems are calculated in Table 4 . They are $1.551 \mathrm{~s}, 0.352 \mathrm{~s}$, and $0.161 \mathrm{~s}$.

To compare the difference of the displacement demand obtained by various $R-\mu-T$ models, it is assumed here that for structures located in the seismic zone of intensity 8 that the PGA under major earthquakes is $0.4 \mathrm{~g}$. The soil condition is type I and the classification lies in group III. Thus, according to the Chinese code and response spectrum (Fig.8.), the seismic coefficient $\alpha_{\max }$ is 0.9 and the characteristic period $T_{g}$ is $0.35 \mathrm{~s}$. (Code for Seismic Design of Buildings, 2008).

The elastic base shearing forces are,

$$
\begin{aligned}
& F_{1 e}=\left(\frac{T_{g}}{T_{1}}\right)^{\gamma} \eta_{2} \alpha_{\max } g=0.249 g, F_{2 e}=\left(\frac{T_{g}}{T_{2}}\right)^{\gamma} \eta_{2} \alpha_{\max } g=0.958 g \\
& F_{3 e}=\eta_{2} \alpha_{\max } g=0.970 \mathrm{~g}
\end{aligned}
$$

\subsection{Determination of elastic and inelastic modes}

Comparing the elastic base shearing force under major earthquakes and equivalent SDOF yield force
Table 3. CANNY Elastic Dynamic Parameter

\begin{tabular}{ccccc}
\hline Floor & Mass $(\mathrm{kN})$ & $\varphi_{1}$ & $\varphi_{2}$ & $\varphi_{3}$ \\
\hline 15 & 6637 & 1.000 & 1.000 & 1.000 \\
14 & 6115 & 0.927 & 0.699 & 0.455 \\
13 & 6115 & 0.851 & 0.384 & -0.101 \\
12 & 6115 & 0.773 & 0.069 & -0.573 \\
11 & 6115 & 0.693 & -0.227 & -0.865 \\
10 & 6115 & 0.611 & -0.487 & -0.919 \\
9 & 6115 & 0.529 & -0.692 & -0.729 \\
8 & 6115 & 0.448 & -0.830 & -0.345 \\
7 & 6115 & 0.368 & -0.893 & 0.138 \\
6 & 6115 & 0.291 & -0.879 & 0.601 \\
5 & 6115 & 0.219 & -0.795 & 0.934 \\
4 & 6115 & 0.153 & -0.653 & 1.000 \\
3 & 6146 & 0.096 & -0.473 & 0.955 \\
2 & 6146 & 0.050 & -0.281 & 0.664 \\
1 & 6146 & 0.016 & -0.107 & 0.286 \\
& $\mathrm{Wt}=92340$ & & & \\
\hline
\end{tabular}

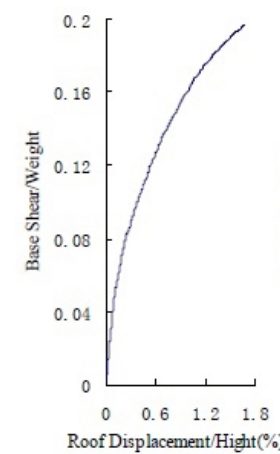

(a)

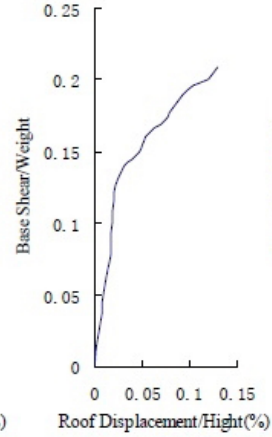

(b)

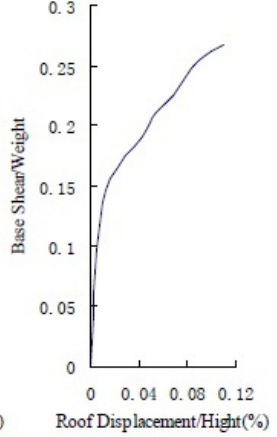

(c)
Fig.7. First Three Modal Pushover Curves in X Direction: (a) First Mode; (b) Second Mode; and (c) Third Mode

(Table 4.), there is,

For the first mode, $R_{I}=0.249 / 0.15=1.66>1$ and the system enters the inelastic stage;

For the second mode, $R_{2}=0.958 / 0.86=1.11>1$ and the system also enters the inelastic stage;

And for the third mode, $R_{3}=0.970 / 5.70=0.17<1$ and the system is still at the elastic stage.

\subsection{Displacements of SDOF systems}

The displacement response of SDOF systems can be obtained by the $R-\mu-T$ model. The Lu-Zhou model is applied here while considering the soil type of China.

In the Lu-Zhou model (Lu and Zhou, 2004), the basic expression of the $R-\mu-T$ model can be expressed in Equation (18), which was proposed by Nassar and Krawinkler (1991).

$$
\mu\left(\xi_{y}, T\right)=\frac{\xi_{y}^{-c}-1}{c}+1
$$

where $c=\frac{T^{a}}{T^{a}+1}+\frac{b}{T}$; and $a$ and $b$ are regression

Table 4. Period Calculation of the Equivalent SDOF Systems

\begin{tabular}{ccccccccc}
\hline Mode & $V_{b v}(\mathrm{kN})$ & $u_{r v}(\mathrm{~mm})$ & $M_{n}(\mathrm{kN} / \mathrm{g})$ & $L_{n}(\mathrm{kN} / \mathrm{g})$ & $\Gamma_{n}$ & $F_{n v} / L_{n}(\mathrm{~g})$ & $D_{n v}(\mathrm{~mm})$ & $T_{n}(\mathrm{~s})$ \\
\hline & & & Eq. $(4)$ & Eq. $(4)$ & Eq. $(4)$ & Eq. $(7)$ & Eq. $(8)$ & Eq. $(10)$ \\
\hline 1 & 9419 & 132 & 29988 & 43485 & 1.450 & 0.15 & 91 & 1.551 \\
2 & 14334 & 18 & 37466 & 24974 & 0.666 & 0.86 & 28 & 0.352 \\
3 & 31950 & 13 & 47026 & 16235 & 0.345 & 5.70 & 38 & 0.161 \\
\hline
\end{tabular}




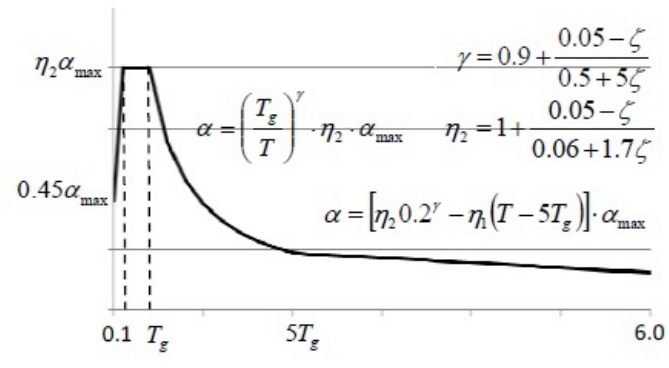

Fig.8. Response Spectra in the Chinese Code ( $\zeta$ is the Damping Ratio)

coefficients of the model.

Using elasto-plastic time history analysis, Lu and Zhou analyzed many SDOF systems under different Chinese soil types and soil classification groups. $a$ and $b$ were obtained as shown in Table 5.

In Table 5., for soil type I and classification group III, $a$ is 0.7115 and $b$ is 0.3640 . Thus, the modal responses of SDOF systems are calculated in Table 6.

\subsection{Displacement of the MDOF system}

From the elastic parameters in Table 3., the displacement responses of SDOF systems under the first three modes can be obtained. Then, the inelastic structural displacements $\Delta$ and inter-story displacements $\theta$ are worked out by an SRSS combination of SDOF systems. Table 7 . lists the displacement demand of the hybrid structure, where $\Delta_{1}, \Delta_{2}$, and $\Delta_{3}$ are displacement demands of the first three modes; and $\theta_{1}, \theta_{2}$, and $\theta_{3}$ are inter-story drifts of the first three modes. The inelastic maximum displacement is $215.6 \mathrm{~mm}$ and the inelastic maximum inter-story drift is $0.0046(1 / 217)$ at 11 and 12 stories, which is less than the code limitation of $1 / 100$.

\subsection{Displacement results of eight models}

The structural inelastic displacements can be calculated by eight $R-\mu-T$ models. To verify the displacement demands, elasto-plastic time-history analysis (THA) is performed under 10 strong earthquake records with a modified PGA of $0.4 \mathrm{~g}$. The response spectra of the strong earthquake records, which are selected according to the Code for Seismic Design of Buildings, are shown in Fig.9. It can be seen that the average values of the selected motions are within the range of 0.8-1.2 times the design response spectra and meet the code requirement.

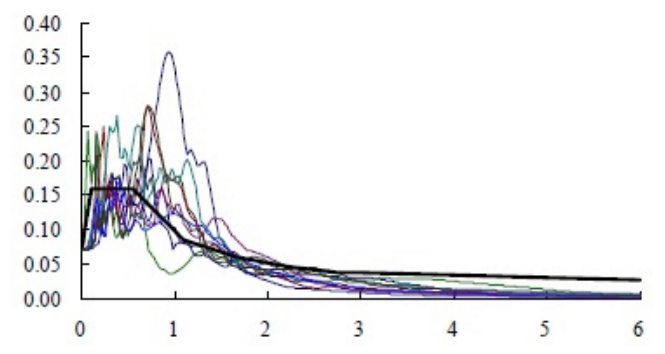

Fig.9. Response Spectra of 10 Ground Motions

Table 5. Regression Values of a and $\mathrm{b}(\mathrm{T}=0.1-3 \mathrm{~s})$

\begin{tabular}{ccccccccc}
\hline Soil Group & \multicolumn{2}{c}{ I } & \multicolumn{2}{c}{ II } & \multicolumn{2}{c}{ III } & \multicolumn{2}{c}{ IV } \\
\hline & $a$ & $b$ & $a$ & $b$ & $a$ & $b$ & $a$ & $b$ \\
\hline 1 & 0.7307 & 0.2363 & 1.8618 & 0.3190 & 0.2729 & 0.2740 & 2.7879 & 0.4276 \\
2 & 1.3431 & 0.3190 & 0.2997 & 0.2505 & 0.3584 & 0.3669 & 1.2508 & 0.4567 \\
3 & 0.7115 & 0.3640 & 0.6675 & 0.4578 & -0.3956 & 0.4253 & 0.3847 & 0.5267 \\
\hline
\end{tabular}

Table 6. Modal Displacement Calculation of the Equivalent SDOF Systems

\begin{tabular}{ccccccc}
\hline Mode & State & Model parameters & Ductility factor & $\begin{array}{c}\text { Inelastic displacement } \\
(\mathrm{mm})\end{array}$ & $\begin{array}{c}\text { Elastic displacement } \\
(\mathrm{mm})\end{array}$ & $\begin{array}{c}\text { Roof displacement } \\
(\mathrm{mm})\end{array}$ \\
\hline & & $c=\frac{T^{a}}{T^{a}+1}+\frac{b}{T}$ & $\mu=\frac{R^{c}-1}{c}+1$ & $D_{n}=\mu_{n} \cdot D_{n y}$ & $D_{n}=T^{2} / 4 \pi^{2} \cdot S_{a}$ & $u_{r m}=\Gamma_{n} \varphi_{m} D_{n}$ \\
\hline 1 & Inelastic & 0.81 & 1.63 & 148 & - & - \\
2 & Inelastic & 1.36 & 1.12 & 31 & 6.4 & 214.6 \\
3 & Elastic & - & - & - & & 2.7 \\
\hline
\end{tabular}

Table 7. Displacement and Inter-Story Drift of the Hybrid Structure

\begin{tabular}{|c|c|c|c|c|c|c|c|c|}
\hline Story & $\begin{array}{c}\Delta_{1} \\
(\mathrm{~mm})\end{array}$ & $\begin{array}{c}\Delta_{2} \\
(\mathrm{~mm})\end{array}$ & $\begin{array}{c}\Delta_{3} \\
(\mathrm{~mm})\end{array}$ & $\begin{array}{c}\Delta \\
(\mathrm{mm})\end{array}$ & $\begin{array}{c}\theta_{1} \\
(\mathrm{rad})\end{array}$ & $\begin{array}{c}\theta_{2} \\
(\mathrm{rad})\end{array}$ & $\begin{array}{c}\theta_{3} \\
(\mathrm{rad})\end{array}$ & $\begin{array}{c}\theta \\
(\mathrm{rad})\end{array}$ \\
\hline 15 & 214.6 & 20.7 & 2.2 & 215.6 & 0.0039 & 0.0016 & 0.0003 & 0.0042 \\
\hline 14 & 198.9 & 14.5 & 1.0 & 199.4 & 0.0041 & 0.0016 & 0.0003 & 0.0044 \\
\hline 13 & 182.6 & 7.9 & -0.2 & 182.8 & 0.0042 & 0.0016 & 0.0003 & 0.0045 \\
\hline 12 & 165.9 & 1.4 & -1.3 & 165.9 & 0.0043 & 0.0015 & 0.0002 & 0.0046 \\
\hline 11 & 148.7 & -4.7 & -1.9 & 148.8 & 0.0044 & 0.0013 & 0.0000 & 0.0046 \\
\hline 10 & 131.1 & -10.1 & -2.0 & 131.5 & 0.0044 & 0.0011 & -0.0001 & 0.0045 \\
\hline 9 & 113.5 & -14.3 & -1.6 & 114.4 & 0.0043 & 0.0007 & -0.0002 & 0.0044 \\
\hline 8 & 96.1 & -17.2 & -0.8 & 97.6 & 0.0043 & 0.0003 & -0.0003 & 0.0043 \\
\hline 7 & 79.0 & -18.5 & 0.3 & 81.1 & 0.0041 & -0.0001 & -0.0003 & 0.0041 \\
\hline 6 & 62.4 & -18.2 & 1.3 & 65.0 & 0.0039 & -0.0004 & -0.0002 & 0.0039 \\
\hline 5 & 47.0 & -16.4 & 2.1 & 49.8 & 0.0035 & -0.0007 & -0.0001 & 0.0036 \\
\hline 4 & 32.8 & -13.5 & 2.3 & 35.5 & 0.0031 & -0.0009 & 0.0001 & 0.0032 \\
\hline 3 & 20.6 & -9.8 & 2.1 & 22.9 & 0.0025 & -0.0010 & 0.0002 & 0.0027 \\
\hline 2 & 10.7 & -5.8 & 1.5 & 12.3 & 0.0018 & -0.0009 & 0.0002 & 0.0020 \\
\hline 1 & 3.4 & -2.2 & 0.6 & 4.1 & 0.0009 & -0.0006 & 0.0002 & 0.0010 \\
\hline
\end{tabular}


Take the average displacement response obtained by THA as the standard, the responses of inelastic RSA, i.e. the $R-\mu-T$ model, are given in Fig.10. It can be seen that:

(1) For the bottom several stories (Story 1-3), the displacement responses of inelastic RSA are smaller than that of the THA. However they are larger at the above stories than the THA result by 5\%-30\%.

(2) As analyzed before, the Newmark-Hall model gives the most conservative result and thus its displacement is the largest.

(3) Four models that considered the site condition, including the Miranda model, Zhuo-Fan model, LuZhou model, and Zhai-Xie model, give larger responses than most without consideration of site characteristics. The difference is within $25 \%$.

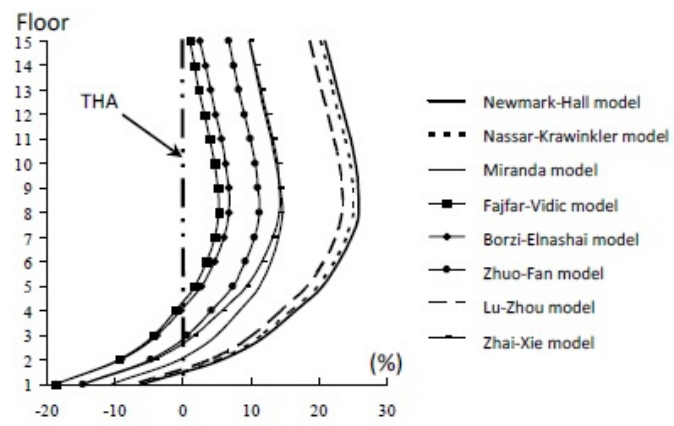

Fig.10. Structural Displacement Demand Differences of $R-\mu-T$ Models

\section{Conclusions}

In this study, eight $R-\mu-T$ models for inelastic response spectrum analysis (RSA) are compared from three aspects in estimating the structural displacement demand of a hybrid structure. First, eight $R-\mu-T$ models are compared concerning their parameters to build the models, including the number of ground motions, parameters of SDOF systems, and site soil considerations. Then, they are analyzed under two constant ductility cases. The applications of eight models to a RC core walls-steel frame hybrid structure are also performed and compared with the result of elasto-plastic time history analysis (THA). From these comparisons, the following conclusions can be reached.

(1) The difference between the displacements obtained by the inelastic RSA of eight models and that by THA is within $30 \%$. Thus, inelastic RSA can work as an effective method in predicting the displacement demand of structures.

(2) The site characteristics do have an effect on the results of various $R-\mu-T$ models. The models giving consideration to the site condition will give larger responses, with a maximum of $25 \%$, than those without consideration of site characteristics. It is suggested that the site characteristics should be introduced to build the $R-\mu-T$ models.

(3) Most models take $5 \%$ as the damping ratio when they are built. No unanimous conclusions are reached on the effect of the damping (damping model and damping ratio) on the $R-\mu-T$ relationship. Further investigation on the damping for $R-\mu-T$ models is needed.

(4) It is also suggested that parameter analysis of various structures be performed to further verify the conclusions.

\section{Acknowledgements}

The authors are grateful for financial support in part from the National Natural Science Foundation of China (Grant No. 51021140006, 50708071 and 51078274) and National Basic Research of China (Grant No. 2007CB714202).

\section{References}

1) Borzi, B. and Elnashai, A. S. (2000) Refined force reduction factors for seismic design, Journal of Engineering Structure 22(5): 1244-1260.

2) China Ministry of Construction (MOC). (2001) Load code for the design of building structures (GB 50009-2001), China Architecture \& Building Press: Beijing, China.

3) China Ministry of Construction (MOC). (2008) Code for Seismic Design of Buildings (GB50011-2001), modified version, China Architecture \& Building Press: Beijing, China.

4) Chopra, A. K. and Goel, R. K. (2002) A modal pushover analysis procedure for estimating seismic demands for buildings, Earthquake Engineering and Structural Dynamics 31(3): 561-582.

5) Fajfar, P. and Vidic, T. (1994) Consistent inelastic design spectra: strength and displacement, Earthquake Engineering and Structural Dynamics 23(5): 507-521.

6) Federal Emergency Management Agency-ASCE. (1997) FEMA 273, NEHRP Guidelines for the Seismic Rehabilitation of Buildings. Washington, DC: Federal Emergency Management Agency-ASCE.

7) Ghobarah, A. (2001) Performance-based design in earthquake engineering: state of development, Engineering Structures 23(8): 878-884.

8) Li, K. N. (2004) 3-Dimensional Nonlinear Static/Dynamic Structural Analysis Computer Program CANNY - Technical Manual. CANNY Consultant Pte Ltd., Canada.

9) Li, K. N. and Kubo, T. (1998) Reviewing the multi-spring model and fiber model, Proceedings of the 10th Japan Earthquake Engineering Symposium Japan, 2, pp. 2369-74.

10) Li, K. N., Kubo, T. and Ventura, C. E. (1999) 3-D analysis of building model and reliability of simulated structural earthquake responses, Proceedings of International Seminar on New Seismic Design Methodologies for Tall Buildings, Beijing, China, pp. 34-41.

11) Li, K. N. and Otani, S. (1993) Multi-spring model for 3-dimensional analysis of RC members, Journal of Structural Engineering and Mechanics 1(1): 17-30.

12) Lu, X. L. and Zhou, D. S. (2004) Ductility demand spectra and inelastic displacement spectra considering soil conditions and design characteristic periods, Earthquake Engineering and Engineering Vibration 24(1): 39-48. (in Chinese)

13) Miranda, E. (1993) Evaluation of site-dependent inelastic seismic design spectra, Journal of Structural Engineering 119(5): 13191339.

14) Miranda, E. (1993) Site-dependent strength-reduction factor, Journal of Structure Engineering 119(12): 3503-3519.

15) Nassar, A. A and Krawinkler, H. (1991) Seismic demands for SDOF and MDOF systems. The John A. Blume Earthquake Engineering Center, Stanford University, Stanford, California, 12-45.

16) Newmark, N. M. and Hall, W. J. (1973) Seismic design criteria for nuclear reactor facilities. Building practices for disaster mitigation, National Bureau of Standard, U.S. Department of Commerce, Washington, 209-236.

17) Sucuoglu, H., Dicleli, M. and Nurtug, A. (1994) An analytical assessment of elastic and inelastic response spectra, Canadian Journal of Civil Engineering 21: 386-395.

18) Zhai, C. H. and Xie, L. L. (2006) Study on the strength reduction factors considering the effect of classification of design earthquake effect, Acta Seismologica Sinica 28(3): 284-294. (in Chinese)

19) Zhuo, W. D. and Fan, L. C. (2001) On strength factors used for seismic design of structures, Earthquake Engineering and Engineering Vibration 21(1): 84-88. (in Chinese) 